\title{
Weight Status and All-Cause Mortality in Older Adults: A Study of Patients With Type 2 Diabetes Undergoing Subtotal Gastrectomy for Cancer
}

\author{
Yeongkeun Kwon ${ }^{1,2}$, Kyeong Jin Kim², ${ }^{2,3}$ Yong Kyun Roh ${ }^{4}$, Yong-Gyu Park ${ }^{5}$, Sungsoo Park ${ }^{2,6}$, Kyung-Hwan Cho ${ }^{1}$ \\ ${ }^{1}$ Division of Geriatrics, Department of Family Medicine, Korea University College of Medicine, Seoul, ${ }^{2}$ Center for Obesity and Metabolic \\ Diseases, Korea University Anam Hospital, Seoul, ${ }^{3}$ Division of Endocrinology and Metabolism, Department of Internal Medicine, Korea \\ University College of Medicine, Seoul, ${ }^{4}$ Department of Family Medicine, Hallym University College of Medicine, Chuncheon, ${ }^{5}$ Department \\ of Biostatistics, College of Medicine, The Catholic University of Korea, Seoul, ${ }^{6}$ Division of Upper Gastrointestinal Surgery, Department \\ of Surgery, Korea University College of Medicine, Seoul, Korea
}

Corresponding Authors:

Kyung-Hwan Cho, MD, MPH, $\mathrm{PhD}$

Division of Geriatrics, Department of Family

Medicine, Korea University College of Medicine, Inchon-ro 73, Seongbuk-gu, Seoul 02841, Korea

Tel: +82-2-920-5105

Fax: +82-2-928-8083

E-mail: chokh@korea.ac.kr

Sungsoo Park, $\mathrm{MD}, \mathrm{PhD}$

Division of Upper Gastrointestinal Surgery, Department of Surgery, Korea University College of Medicine, Inchon-ro 73, Seongbuk-gu, Seoul 02841, Korea

Tel: $+82-2-920-6772$

Fax: +82-2-928-1631

E-mail: kugspss@korea.ac.kr

Received: April 19, 2017

Revised: June 9, 2017

Accepted: June 11, 2017
Background: The survival benefit of excess body weight is controversial across various subpopulations. We assessed the effect of weight status on all-cause mortality among patients with type 2 diabetes (T2DM) undergoing subtotal gastrectomy for gastric cancer. Methods: Medical charts of 210 patients with T2DM treated at 2 university hospitals were examined retrospectively. All patients had undergone subtotal gastrectomy for cancer between January 1993 and December 2012. Participants were categorized as normal weight (body mass index [BMI], $\left.18.5-24.99 \mathrm{~kg} / \mathrm{m}^{2}\right)$ or overweight/obese $\left(B M I \geq 25 \mathrm{~kg} / \mathrm{m}^{2}\right)$. The association between weight status and all-cause mortality was assessed using weighted Cox proportional hazard regression models and inverse probability weighting. Results: The mortality rate was $25.2 \%$ after a median follow-up duration of 6.1 years (interquartile range, $3.5-8.3$ years; maximum, 14.4 years). The overweight/obese group had a significantly lower risk of all-cause mortality (hazard ratio, 0.51; $95 \%$ confidence interval, $0.34-0.77 ; \mathrm{p}=0.001$ ) compared with the normal weight group. Overweight/obesity was associated with reduced all-cause mortality in patients aged $<65$ years ( $p=0.01$ for interaction). Conclusion: Among T2DM patients who underwent subtotal gastrectomy for cancer, only the subgroup of patients aged $<65$ years in the overweight/obese group showed reduced allcause mortality compared with the normal weight group.

Key Words: Type 2 diabetes, Body mass index, Subtotal gastrectomy, Stomach neoplasms, Mortality

\section{INTRODUCTION}

Excess body weight is associated with negative health outcomes, including diabetes, cancer, and all-cause mortality $^{1-4)}$; however, it has been difficult to address heterogeneity of the effect of weight status on mortality according to population characteristics, especially in older adults ${ }^{5-7)}$. Considering that detecting heterogeneity of the weight status effect poses serious analytical challenges, attempting to define a subpopulation group and assess group-specific results is essential ${ }^{8)}$.

We confined our study population to patients with con- current gastric cancer and type 2 diabetes (T2DM) who underwent subtotal gastrectomy for cancer, considering the potential effects of those 2 diseases and surgery on weight status and mortality. Patients with gastric cancer are generally older adults, and overall survival of this cancer seems to be increasing with progress in surgery and perioperative medicine ${ }^{9,10)}$. Cancer often induces progressive weight loss by the cachectic process or anorexia ${ }^{11)}$, and postoperative weight loss is well recognized as a reduction in calorie intake and malabsorption ${ }^{12)}$.

T2DM also influences weight status due to medical treatments or lifestyle modifications after diagnosis, and patients with diabetes have approximately twice the mortality risk 
of individuals without diabetes ${ }^{13)}$. T2DM status has been known to be influenced by gastrectomy for cancer and postoperative weight loss ${ }^{14,15)}$. According to a previous meta-analysis, about half of nonobese T2DM patients experienced diabetes improvement after subtotal gastrectomy for cancer ${ }^{16)}$.

The aims of the present study were, first, to assess the weight status effect on mortality in T2DM patients undergoing subtotal gastrectomy for cancer, and second, to identify any potential baseline characteristics, including age, that could differentiate patients with and without survival benefits.

\section{MATERIALS AND METHODS}

\section{Study Population}

The medical charts of 2,085 patients with gastric cancer who had undergone a radical subtotal gastrectomy between January 1993 and December 2012 at 2 university hospitals were retrospectively reviewed. Patients who did not have diabetes or had a body mass index (BMl; weight in kilograms divided by height in meters squared) $<18.5 \mathrm{~kg} / \mathrm{m}^{2}$, diabetes secondary to a specific disease or glucocorticoid treatment, other endocrinopathies, surgical history of other organ resection, distant metastasis, and recurrence of gastric cancer were excluded from this study. A total 210 T2DM patients were consequently included. Informed consent was obtained from all patients before surgery. This study was approved by the Institutional Review Board (approval number: ED 14008).

\section{T2DM and Weight Status}

T2DM was diagnosed using either fasting plasma glucose levels or oral glucose tolerance test results, in accordance with the American Diabetes Association ${ }^{17)}$. Patients were considered to have diabetes if they had a history of diabetes and diabetes medication use. Normal weight, overweight, and obesity were defined as BMI $18.5-24.9 \mathrm{~kg} / \mathrm{m}^{2}, 25-29.9$ $\mathrm{kg} / \mathrm{m}^{2}$, and $\geq 30 \mathrm{~kg} / \mathrm{m}^{2}$, respectively ${ }^{18)}$. Participants were classified according to their weight status at gastric cancer diagnosis.

\section{Surgical Procedures}

Participants in this study had undergone a subtotal gastrectomy to treat gastric cancer lesions in the distal part of the stomach. The extent of resection was determined according to the location of the primary tumor and lymph node status. Patients underwent Billroth I (BI) reconstruction following a complete Kocher maneuver in order to mobilize the duodenum and a tension-free, side-to-end hand-sutured gastroduodenostomy. For patients undergoing Billroth II (BII) reconstruction, the duodenum was transected approximately
$2 \mathrm{~cm}$ distal to the pylorus with a linear stapler, followed by a distal gastrectomy and Bll anastomosis using a hand-sutured or stapled technique. Hand-sutured extracorporeal anastomosis was performed between the gastric remnant and the chosen jejunal loop, approximately $10-15 \mathrm{~cm}$ distal to the ligament of Treitz. BII reconstruction was selected for cases in which the tumor was close to the pylorus, suprapyloric and infrapyloric lymph node invasion was noted, or the tension was too high to perform $\mathrm{Bl}$ anastomosis. $\mathrm{Bl}$ reconstruction was performed for intestinal continuity. A vagotomy was routinely performed during lymph node dissection in all patients.

\section{Postoperative Management}

All patients returned to our centers for follow-up at least every 6 months during the first 3-year postsurgery. Complete evaluations were performed on all patients, both prior to surgery and during the follow-up period. Routine follow-up included a review of prescribed medication, an assessment of nutritional behaviors, anthropometric and clinical parameter measurements, and blood sampling for laboratory tests. In this study, no patients received neoadjuvant chemotherapy or radiotherapy; patients with stage II or higher cancers were treated postoperatively with 5-fluorouracil-based adjuvant chemotherapy.

\section{Main Outcome Measures and Covariates}

The primary outcome of this study was all-cause mortality, which is a robust and unbiased index that does not require adjudication to avoid biased clinical assessments or documentation ${ }^{19)}$. Follow-up mortality data through December 31, 2013 were validated with information obtained from the Korean National Statistical Office's Microdata Service System, using a unique personal identification number.

The covariates in this study included age, sex, BMI, glycated hemoglobin level, fasting plasma glucose level, hypoglycemia medications, smoking status, total cholesterol level, blood pressure, cancer stage, adjuvant chemotherapy, type of reconstruction, and Charlson comorbidity index measured at baseline. Gastric cancer staging was performed according to the American Joint Committee on Cancer staging manual $^{20)}$. We used the Charlson comorbidity index, which has been used to compare various comorbidities according to the strength of their relationships with mortality, to quantify the comorbidity burden ${ }^{21)}$.

\section{Statistical Analyses}

Categorical and continuous variables were presented as percentages and mean \pm standard deviation (SD), respectively. 
Patient characteristics at baseline were stratified by weight status and compared using the Pearson chi-square test for categorical variables and Student t-test or Mann-Whitney test for continuous variables. Kaplan-Meier survival curves with log-rank chi-square were used to compare mortality by weight status.

Multivariable Cox proportional hazards regression models were used to estimate adjusted hazard ratios for investigating the association between weight status and all-cause mortality. Variables with a $p$-value $\leq 0.20$ in the univariate analyses were considered for the multivariable Cox regression model. We used a backward elimination process (variables with $p<0.05$ were retained) to build the multivariable model. Log-log survival plots were used to evaluate the proportional hazards assumption, and no relevant violation was found.

To reduce the potential for confounding in this observational study, results were rigorously adjusted for differences in patient baseline characteristics using weighted Cox proportional hazards regression models with inverse probability weighting (IPW $)^{22)}$. Weights for normal weight and overweight/obese patients were calculated as the inverse of 1 minus propensity score and inverse of the propensity score, respectively. Propensity scores were estimated using multiple logistic regression analysis regardless of the outcomes. We developed a full nonparsimonious model including the variables presented in Table 1. Model discrimination was assessed using the C-statistic, and model calibration was estimated using the Hosmer-Lemeshow test. The model was found to be well calibrated, with reasonable discrimination (C-statistic $=0.71$ ) based on overall data (Hosmer-Lemeshow test; $\mathrm{p}=0.24)$.

To evaluate whether the effect of weight status varied across subgroups, we tested the interaction between group assignments and risk factor categories. Differences in the effect of overweight/obese between subgroups were assessed with a Cox proportional hazards model, by including an interaction term between the subgroup category and the study group. Statistical analyses were performed using Stata 13 (Stata Corp., College Station, TX, USA). A 2-tailed $p$-value $<0.05$ was considered statistically significant.

\section{RESULTS}

\section{Baseline Characteristics}

The mean age of the study population was 64.3 years (SD, 8.7 years), and $71.0 \%$ of patients were men (Table 1). Within the study population, $32.4 \%$ and $67.6 \%$ of patients underwent $\mathrm{BI}$ and $\mathrm{BII}$ reconstruction, respectively. Patients with stage I gastric cancer comprised the largest proportion of the study population $(73.3 \%)$, followed by those with stage II (16.7\%) and stage III (10.0\%) cancers. Of all patients en-

Table 1. Distribution of covariates stratified by weight status

\begin{tabular}{|c|c|c|c|}
\hline Characteristic & Normal weight $(n=126)$ & Overweight/obese $(n=84)$ & p-value* \\
\hline Age (yr) & $64.5 \pm 8.9$ & $64.0 \pm 8.4$ & 0.65 \\
\hline Female sex & $28(22.2)$ & $33(39.3)$ & 0.008 \\
\hline Body mass index $\left(\mathrm{kg} / \mathrm{m}^{2}\right)$ & $22.3 \pm 1.9$ & $27.3 \pm 2.0$ & $<0.001$ \\
\hline \multicolumn{4}{|l|}{ Diabetes factors } \\
\hline Glycated hemoglobin (\%) & $7.31 \pm 1.30$ & $7.37 \pm 1.40$ & 0.74 \\
\hline Fasting plasma glucose $(\mathrm{mg} / \mathrm{dL})$ & $149.9 \pm 55.4$ & $147.5 \pm 44.5$ & 0.74 \\
\hline Disease duration $(\mathrm{yr})$ & $8.2 \pm 6.8$ & $6.4 \pm 5.6$ & 0.04 \\
\hline $\begin{array}{l}\text { Hypoglycemic medications } \\
\text { Insulin:OHA:no use }\end{array}$ & $11: 104: 11(8.7: 82.5: 8.7)$ & $9: 71: 4(10.7: 84.5: 4.8)$ & 0.51 \\
\hline Ever smoked & $27(21.4)$ & $15(17.9)$ & 0.53 \\
\hline Total cholesterol (mg/dL) & $165.7 \pm 36.8$ & $169.1 \pm 38.0$ & 0.52 \\
\hline Systolic blood pressur (mmHg) & $122.1 \pm 12.8$ & $123.3 \pm 14.2$ & 0.53 \\
\hline Diastolic blood pressure (mmHg) & $76.7 \pm 8.5$ & $77.0 \pm 8.5$ & 0.82 \\
\hline Blood pressure medications & $62(49.2)$ & $52(61.9)$ & 0.07 \\
\hline $\begin{array}{l}\text { Cancer stage } \\
\text { I:II:III }\end{array}$ & $97: 21: 8(77.0: 16.7: 6.3)$ & $57: 14: 13(67.9: 6.7: 15.5)$ & 0.09 \\
\hline Adjuvant chemotherapy & $45(35.7)$ & $35(41.7)$ & 0.38 \\
\hline $\begin{array}{l}\text { Type of reconstruction } \\
\text { Billroth I:Billroth II }\end{array}$ & $43: 83(34.1: 65.9)$ & $25: 59(29.8: 70.2)$ & 0.51 \\
\hline $\begin{array}{l}\text { Charlson comorbidity index } \\
1: 2: 3\end{array}$ & 91:20:15 (72.2:15.9:11.9) & 68:8:8 (81.0:9.5:9.5) & 0.32 \\
\hline
\end{tabular}

Values are presented as mean \pm standard deviation or number (\%).

Normal weight, BMI $=18.5-24.9 \mathrm{~kg} / \mathrm{m}^{2}$; overweight $/$ obese, BMI $\geq 25 \mathrm{~kg} / \mathrm{m}^{2}$.

OHA, oral hypoglycemic agent.

*p-values obtained by t-test and chi-square test. 
rolled in this study, 38.1\% received adjuvant chemotherapy. The groups were similar for all observed characteristics, except for the proportion of female patients (normal weight, 22.2\%; overweight/obese, 39.3\%; $\mathrm{p}=0.008$ ), mean BMI (normal weight, $22.3 \mathrm{~kg} / \mathrm{m}^{2}$; overweight/obese, $27.3 \mathrm{~kg} / \mathrm{m}^{2} ; p<$ 0.001 ), and mean diabetes duration (normal weight, 8.2 years; overweight/obese, 6.4 years; $p=0.04$ ).

The normal weight group had a mean age of 64.5 years (SD, 8.9 years), glycated hemoglobin level of $7.31 \%$ (SD, $1.30 \%$ ), and fasting plasma glucose level of $149.9 \mathrm{mg} / \mathrm{dL}$ (SD, $55.4 \mathrm{mg} / \mathrm{dL}$ ). Within the normal weight group, $8.7 \%$ and $49.2 \%$ of patients used insulin therapy and blood pressure medication, respectively. The overweight/obese group had a mean age of 64.0 years (SD, 8.4 years), glycated hemoglobin level of $7.37 \%$ (SD, 1.40\%), and fasting plasma glucose level of $147.5 \mathrm{mg} / \mathrm{dL}$ (SD, $44.5 \mathrm{mg} / \mathrm{dL}$ ). Within the overweight/obese group, $10.7 \%$ and $61.9 \%$ of patients used insulin therapy and blood pressure medication, respectively.

\section{All-Cause Mortality}

The mortality rate was $25.2 \%$ (normal weight, $30.2 \%$; overweight/obese, $17.9 \%$ ) after a median follow-up duration of 6.1 years (interquartile range, 3.5-8.3 years; maximum, 14.4 years). A borderline significant difference in mortality risk was shown between the groups (Fig. 1) in the Kaplan-Meier curve (log-rank chi-square $=2.9, p=0.08)$. According to multivariable Cox proportional hazards regression analyses, overweight/obese was independently associated with a decreased risk of all-cause mortality compared with normal weight (hazard ratio [HR], 0.49; 95\% confidence interval [Cl], 0.26-0.94; $\mathrm{p}=0.03$ ) (Table 2). After IPW adjustment, patients in the overweight/obese group continued to have significantly lower all-cause mortality compared with those in the normal weight group (HR, 0.51; 95\% Cl, 0.34-0.77; $p=0.001)$.

\section{Subgroup Analyses}

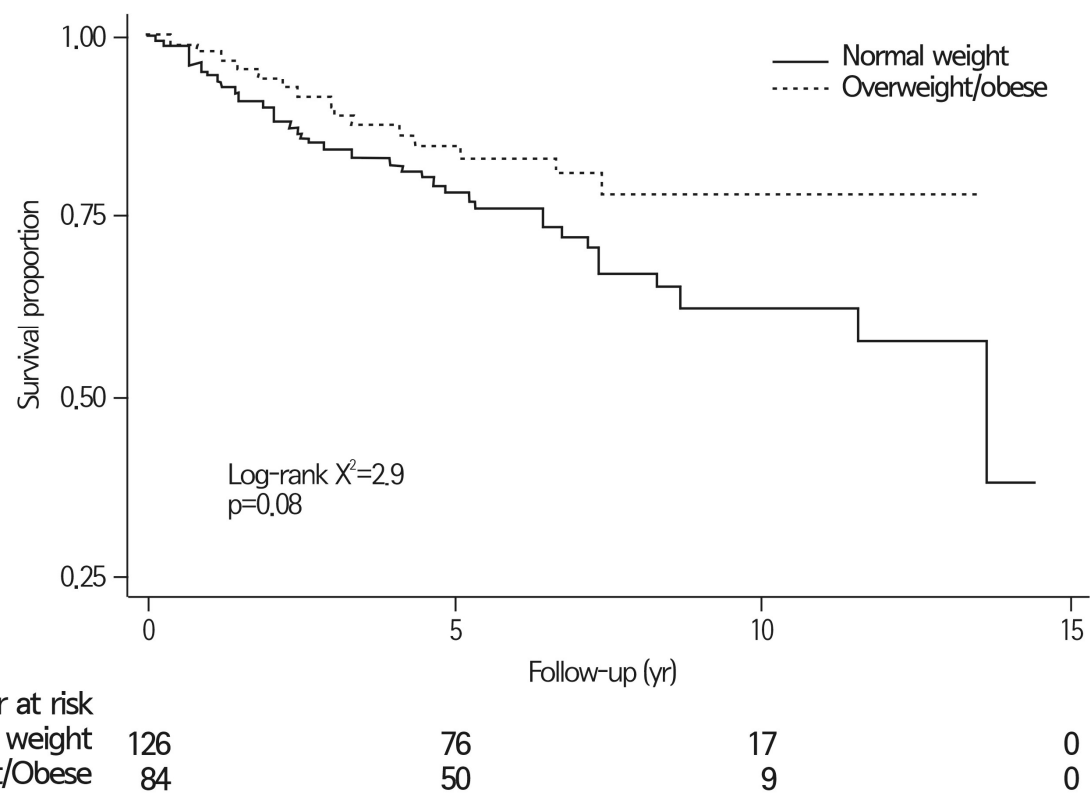

Fig. 1. Kaplan-Meier survival estimates of all-cause mortality in patients stratified by weight status. Normal weight was defined as body mass index (BMI) $18.5-24.9 \mathrm{~kg} / \mathrm{m}^{2}$; patients categorized as overweight/obese had BMI $\geq 25 \mathrm{~kg} / \mathrm{m}^{2}$.

Table 2. Associations between body mass index or weight status and all-cause mortality

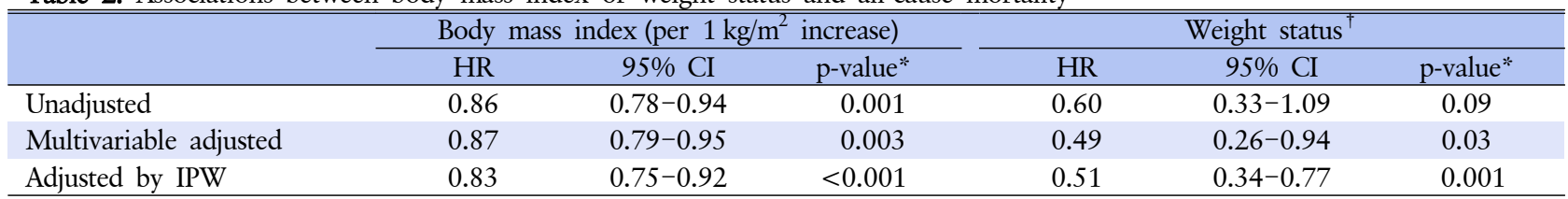

HR, hazard ratio; CI, confidence interval; IPW, inverse probability weighting using propensity score.

*p-values obtained by weighted Cox proportional hazard regression models and inverse probability weighting. ${ }^{\dagger}$ Overweight/obese patients compared with normal weight patients. 
Yeongkeun Kwon, et al.

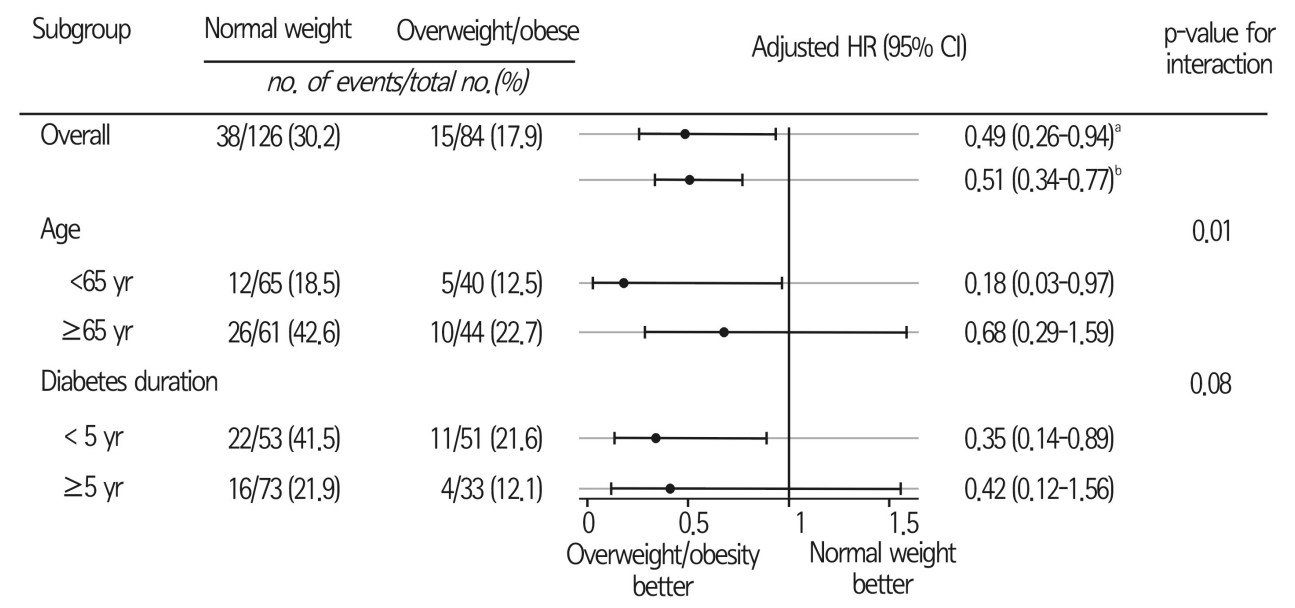

Fig. 2. Forest plots for all-cause mortality. Adjusted hazard ratios for all-cause mortality based on subgroups in the overweight/obese group compared with the normal weight group. (A) Multivariable adjusted; (B) inverse probability weighting adjusted (see Table 2).

A significant interaction was identified between the study groups and age ( $p=0.01$ for interaction) whereas a borderline interaction was observed for diabetes duration $(p=0.08$ for interaction; Fig. 2). The risk of all-cause mortality did not decrease in patients aged $\geq 65$ years (mean, 71.1 years) in the overweight/obese group compared with the normal weight group ( $\mathrm{HR}, 0.68 ; 95 \% \mathrm{Cl}, 0.29-1.59)$. The risk of allcause mortality was significantly reduced in patients aged $<65$ years (mean, 57.5 years) in the overweight/obese group compared with the normal weight group ( $\mathrm{HR}, 0.18 ; 95 \% \mathrm{Cl}$, $0.03-0.97)$. A reduced risk of all-cause mortality was observed in patients with diabetes duration $<5$ years (mean, 2.9 years) in the overweight/obese group compared with patients in the normal weight group ( $\mathrm{HR}, 0.35 ; 95 \% \mathrm{Cl}, 0.14-0.89)$. However, the risk of all-cause mortality in men with diabetes duration $\geq 5$ years (mean, 12.0 years) was not significantly different between the groups ( $\mathrm{HR}, 0.42 ; 95 \% \mathrm{Cl}, 0.12-1.56)$.

\section{DISCUSSION}

To our knowledge, this study is the first to evaluate the heterogeneity of weight status effect on long-term survival among patients with T2DM undergoing subtotal gastrectomy for gastric cancer. We showed that patients with T2DM who were overweight or obese had a lower all-cause mortality rate compared to normal weight patients after undergoing subtotal gastrectomy for cancer. Significant and borderline interactions between age and diabetes duration were identified within the study groups. The results of the present study were consistent with prior studies in other prevalent cohorts, including studies conducted among patients with diabetes ${ }^{23-26)}$.

The methodologic challenges to evaluating the impact of weight status on mortality in older adults are considerable. Compared with other age groups, older adults usually have multiple health risks and decreased life expectancy, so single-cause mortality has less influence on survival as the patient ages ${ }^{27)}$. In addition, reverse causality attributable to illness-associated weight loss most strongly affects estimates derived from older adults. Appropriate statistical analysis for evaluating the heterogeneity of risk factor effects on subgroups begins with subgroup analysis and a statistical test for interaction ${ }^{28,29)}$.

In the purported obesity paradox, the survival benefits of overweight or obesity have been reported in patients with heart failure, hypertension, end-stage renal disease, and more recently, in patients with $\mathrm{T}_{2} \mathrm{DM}^{23,25,26,30-32)}$. However, gastrectomy for cancer is a potentially novel setting for assessing this phenomenon among patients with T2DM. Gastric cancer remains the most prevalent cancer in East Asia ${ }^{33)}$. The age at presentation is increasing among patients with gastric cancer ${ }^{9}$, specifically in South Korea, and gastric cancer has become more common in older adults, with $16.1 \%$ of patients aged $\geq 70$ years ${ }^{10)}$. Malnutrition has been widely recognized in patients with gastric cancer, either owing to the disease itself or owing to surgical and oncological treatment. For example, patients who undergo gastrectomy lose $7 \%$ to $15 \%$ of their body weight, usually within a year after surgery, and do not return to a preoperative weight ${ }^{12)}$. Gastrectomy itself improves the glycemic control of patients with T2DM, independent of postoperative weight loss ${ }^{15}$.

According to the findings of the present study, a survival benefit was observed in a subgroup of overweight/obese patients aged $<65$ years but not in those aged $\geq 65$ years. Human aging could shift the association between BMI and lower risk of mortality. Older adults aged $>70$ years appear to have BMls that are related to reduced mortality risk across the overweight or class I obese range ${ }^{34)}$; however, the reduced mortality risk is either lower or not observed in adults with 
more severe levels of obesity compared with those in the overweight or class I obese range. Mean BMI (27.3; SD, 2.0 $\mathrm{kg} / \mathrm{m}^{2}$ ) in the younger overweight/obese group in the present study was mainly in the overweight range, which is nearly equal to the optimal BMI for reduced mortality. However, a higher optimal BMI for reduced mortality in the older subgroup compared with the younger subgroup resulted in the loss of significance of the lower mortality rate observed in the overweight/obese group; this might be explained by higher perioperative mortality compared with the younger group $^{35)}$. In a bariatric surgical study involving a population of older veterans in the United States, no mortality advantage associated with weight reduction was demonstrated ${ }^{36)}$. Further assessment for the heterogeneity among older adults of concurrent gastric cancer and T2DM is needed.

In the present study, a lower mortality rate in the overweight/obese group was observed only in a subgroup of patients with diabetes duration $<5$ years (Fig. 2). New-onset T2DM in older adults appears to have a benign course compared with long-term T2DM, which could have a less confounding effect on the lower mortality rate of the overweight/obese group in our study. Long-term diabetes has not shown an association with survival advantage, and senile diabetes does not significantly change the clinical course ${ }^{377}$. New-onset T2DM in older adults is related to both improved glucose contro ${ }^{38)}$ and a lower frequency of microvascular complications, as compared with long-term diabetes ${ }^{39)}$. In addition, according to a previous meta-analysis, diabetes duration of $<5$ years is a clinical predictor for identifying possible diabetes improvement in patients undergoing subtotal gastrectomy for cancer ${ }^{16)}$.

This study had several limitations. First, because the study population consisted of Korean adults, the results might not be generalized to other ethnic groups. In particular, considering ethnic differences in obesity or fat deposition, Asian populations show a higher prevalence of diabetes compared with BMI- and waist circumference-matched Western population groups ${ }^{40,41)}$. Second, we did not consider each patient's postoperative diabetes status in the survival analysis. The remission or improvement of T2DM after subtotal gastrectomy to treat gastric cancer might influence the weight status effect on mortality. BMI and diabetes duration have been identified as clinical predictors for identifying possible T2DM amelioration in patients undergoing subtotal gastrectomy for cancer (higher BMI or diabetes duration $<5$ years $)^{16)}$. Although we considered these factors when constructing a statistical model of survival analysis, this issue should be assessed in additional studies. Third, different surgery types have different effects on T2DM and postoperative BMI changes ${ }^{42,43)}$. We only included subtotal gastrectomy cases, to decrease the confounding effects of the extent of gastrectomy. Further research is required to assess the effect of the extent of gastrectomy and various reconstruction methods. Finally, owing to this study's retrospective and nonrandomized design, it is possible that other unknown factors could confound the association between weight status and mortality among T2DM patients undergoing subtotal gastrectomy for cancer.

Nevertheless, considering the novel concept of assessing the heterogeneity of weight status effect on long-term survival among T2DM patients undergoing subtotal gastrectomy, we believe that our study provides important clues for the treatment of patients with concurrent gastric cancer and T2DM, who are generally older adult patients. Further research should be conducted to identify the mechanism of this response and to determine the associations with other groups of patients with diabetes, surgical patient groups, or subtypes that have been assessed thus far, if any, using only small groups.

In summary, among participants aged $<65$ years and possibly in patients with diabetes duration $<5$ years who had undergone subtotal gastrectomy for cancer, significantly reduced all-cause mortality risk was observed in the overweight/obese group compared with the normal weight group. A more precise index of weight status reflecting mortality, rather than BMI, is needed for the population of patients with T2DM undergoing subtotal gastrectomy for cancer.

Conflicts of Interest Disclosures: The researchers claim no conflicts of interest.

\section{REFERENCES}

1. Berrington de Gonzalez A, Hartge P, Cerhan JR, Flint AJ, Hannan L, MacInnis RJ, et al. Body-mass index and mortality among 1.46 million white adults. N Engl J Med 2010;363:2211-9.

2. Calle EE, Thun MJ. Obesity and cancer. Oncogene 2004;23: 6365-78.

3. Chan JM, Rimm EB, Colditz GA, Stampfer MJ, Willett WC. Obesity, fat distribution, and weight gain as risk factors for clinical diabetes in men. Diabetes Care 1994;17:961-9.

4. Colditz GA, Willett WC, Rotnitzky A, Manson JE. Weight gain as a risk factor for clinical diabetes mellitus in women. Ann Intern Med 1995;122:481-6.

5. Adams KF, Schatzkin A, Harris TB, Kipnis V, Mouw T, BallardBarbash R, et al. Overweight, obesity, and mortality in a large prospective cohort of persons 50 to 71 years old. N Engl J Med 2006;355:763-78.

6. Flegal KM, Graubard BI, Williamson DF, Gail MH. Cause-specific excess deaths associated with underweight, overweight, and obesity. JAMA 2007;298:2028-37.

7. Pischon T, Boeing H, Hoffmann K, Bergmann M, Schulze MB, Overvad K, et al. General and abdominal adiposity and risk of death in Europe. N Engl J Med 2008;359:2105-20.

8. Wang R, Schoenfeld DA, Hoeppner B, Evins AE. Detecting treatment-covariate interactions using permutation methods. 
Stat Med 2015;34:2035-47.

9. Borch K, Jönsson B, Tarpila E, Franzén T, Berglund J, Kullman $\mathrm{E}$, et al. Changing pattern of histological type, location, stage and outcome of surgical treatment of gastric carcinoma. $\mathrm{Br} \mathrm{J}$ Surg 2000;87:618-26.

10. Ahn HS, Lee HJ, Yoo MW, Jeong SH, Park DJ, Kim HH, et al. Changes in clinicopathological features and survival after gastrectomy for gastric cancer over a 20-year period. Br J Surg 2011;98:255-60.

11. Inui A. Cancer anorexia-cachexia syndrome: current issues in research and management. CA Cancer J Clin 2002;52:72-91.

12. Heneghan HM, Zaborowski A, Fanning M, McHugh A, Doyle S, Moore J, et al. Prospective study of malabsorption and malnutrition after esophageal and gastric cancer surgery. Ann Surg 2015;262:803-7.

13. Emerging Risk Factors Collaboration, Seshasai SR, Kaptoge S, Thompson A, Di Angelantonio E, Gao P, et al. Diabetes mellitus, fasting glucose, and risk of cause-specific death. N Engl J Med 2011;364:829-41.

14. Cohen RV, Pinheiro JC, Schiavon CA, Salles JE, Wajchenberg BL, Cummings DE. Effects of gastric bypass surgery in patients with type 2 diabetes and only mild obesity. Diabetes Care 2012; 35:1420-8.

15. Kwon Y, Abdemur A, Lo Menzo E, Park S, Szomstein S, Rosenthal RJ. The foregut theory as a possible mechanism of action for the remission of type 2 diabetes in low body mass index patients undergoing subtotal gastrectomy for gastric cancer. Surg Obes Relat Dis 2014;10:235-42.

16. Kwon Y, Jung Kim H, Lo Menzo E, Park S, Szomstein S, Rosenthal RJ. A systematic review and meta-analysis of the effect of Billroth reconstruction on type 2 diabetes: A new perspective on old surgical methods. Surg Obes Relat Dis 2015;11:1386-95.

17. Standards of medical care in diabetes-2017: summary of revisions. Diabetes Care 2017;40(Suppl 1):S4-5.

18. WHO Expert Consultation. Appropriate body-mass index for Asian populations and its implications for policy and intervention strategies. Lancet 2004;363:157-63.

19. Lauer MS, Blackstone EH, Young JB, Topol EJ. Cause of death in clinical research: time for a reassessment? J Am Coll Cardiol 1999;34:618-20.

20. Edge SB, Compton CC. The American Joint Committee on Cancer: the 7th edition of the AJCC cancer staging manual and the future of TNM. Ann Surg Oncol 2010;17:1471-4.

21. Charlson ME, Pompei P, Ales KL, MacKenzie CR. A new method of classifying prognostic comorbidity in longitudinal studies: development and validation. J Chronic Dis 1987;40: 373-83.

22. Robins JM, Hernán MA, Brumback B. Marginal structural models and causal inference in epidemiology. Epidemiology 2000; 11:550-60.

23. Doehner W, Erdmann E, Cairns R, Clark AL, Dormandy JA, Ferrannini $\mathrm{E}$, et al. Inverse relation of body weight and weight change with mortality and morbidity in patients with type 2 diabetes and cardiovascular co-morbidity: an analysis of the PROactive study population. Int J Cardiol 2012;162:20-6.

24. McEwen LN, Kim C, Karter AJ, Haan MN, Ghosh D, Lantz PM, et al. Risk factors for mortality among patients with diabetes: the Translating Research Into Action for Diabetes
(TRIAD) Study. Diabetes Care 2007;30:1736-41.

25. Carnethon MR, De Chavez PJ, Biggs ML, Lewis CE, Pankow JS, Bertoni AG, et al. Association of weight status with mortality in adults with incident diabetes. JAMA 2012;308:581-90.

26. Logue J, Walker JJ, Leese G, Lindsay R, McKnight J, Morris A, et al. Association between BMI measured within a year after diagnosis of type 2 diabetes and mortality. Diabetes Care 2013; 36:887-93.

27. Welch HG, Albertsen PC, Nease RF, Bubolz TA, Wasson JH. Estimating treatment benefits for the elderly: the effect of competing risks. Ann Intern Med 1996;124:577-84.

28. Gail M, Simon R. Testing for qualitative interactions between treatment effects and patient subsets. Biometrics 1985;41:36172.

29. Simon R. Patient subsets and variation in therapeutic efficacy. Br J Clin Pharmacol 1982;14:473-82.

30. Lavie CJ, Milani RV, Ventura HO, Romero-Corral A. Body composition and heart failure prevalence and prognosis: getting to the fat of the matter in the "obesity paradox". Mayo Clin Proc 2010;85:605-8.

31. Schmidt D, Salahudeen A. The obesity-survival paradox in hemodialysis patients: why do overweight hemodialysis patients live longer? Nutr Clin Pract 2007;22:11-5.

32. Uretsky S, Messerli FH, Bangalore S, Champion A, CooperDehoff RM, Zhou Q, et al. Obesity paradox in patients with hypertension and coronary artery disease. Am J Med 2007;120: 863-70.

33. Bray F, Ren JS, Masuyer E, Ferlay J. Global estimates of cancer prevalence for 27 sites in the adult population in 2008. Int J Cancer 2013;132:1133-45.

34. Flegal KM, Graubard BI, Williamson DF, Gail MH. Excess deaths associated with underweight, overweight, and obesity. JAMA 2005;293:1861-7.

35. Livingston EH, Arterburn D, Schifftner TL, Henderson WG, DePalma RG. National Surgical Quality Improvement Program analysis of bariatric operations: modifiable risk factors contribute to bariatric surgical adverse outcomes. J Am Coll Surg 2006;203:625-33.

36. Maciejewski ML, Livingston EH, Smith VA, Kavee AL, Kahwati LC, Henderson WG, et al. Survival among high-risk patients after bariatric surgery. JAMA 2011;305:2419-26.

37. Motta M, Bennati E, Capri M, Ferlito L, Malaguarnera M. Diabetes mellitus in the extreme longevity. Exp Gerontol 2008; 43:102-5.

38. Berkowitz SA, Meigs JB, Wexler DJ. Age at type 2 diabetes onset and glycaemic control: results from the National Health and Nutrition Examination Survey (NHANES) 2005-2010. Diabetologia 2013;56:2593-600.

39. Wang Y, Qin MZ, Liu Q, Liu Q, Chang ZW. Clinical analysis of elderly patients with elderly-onset type 2 diabetes mellitus in China: assessment of appropriate therapy. J Int Med Res 2010;38:1134-41.

40. Hsu WC, Boyko EJ, Fujimoto WY, Kanaya A, Karmally W, Karter A, et al. Pathophysiologic differences among Asians, native Hawaiians, and other Pacific Islanders and treatment implications. Diabetes Care 2012;35:1189-98.

41. Choi J. Obesity defined by body mass index and metabolic status in the elderly. J Korean Geriatr Soc 2011;15:222-9. 
42. Lee W, Ahn SH, Lee JH, Park DJ, Lee HJ, Kim HH, et al. Comparative study of diabetes mellitus resolution according to reconstruction type after gastrectomy in gastric cancer patients with diabetes mellitus. Obes Surg 2012;22:1238-43.

43. Kim JW, Jung SY, Cho JW, Kim BC, Chung KS, Yang DH.
Postoperative body mass index changes in gastric cancer patients according to reconstruction type: effectiveness of long jejunal bypass on weight loss in obese patients after distal gastrectomy. Indian J Surg 2014;76:187-92. 